\title{
Quality, Excellence and Culture in the Pursuit of Organizational Agility
}

\author{
A. M. Carvalho ${ }^{1,2}$, P. Sampaio ${ }^{2}$, E. Rebentisch ${ }^{3}$, P. Saraiva ${ }^{4}$ \\ ${ }^{1}$ Engineering Design and Advanced Manufacturing Focus Area, MIT Portugal Program, Portugal/USA \\ ${ }^{2}$ Department of Production and Systems Engineering, University of Minho, Braga, Portugal \\ ${ }^{3}$ Sociotechnical Systems Research Center, Massachusetts Institute of Technology, Cambridge, USA \\ ${ }^{4}$ Department of Chemical Engineering, University of Coimbra, Coimbra, Portugal \\ ${ }^{1}$ (andre.carvalho@dps.uminho.pt)
}

\begin{abstract}
Operational excellence programs have proved to be valuable in helping companies improve their quality practices and their performance. However, after some time, these programs seem to stagnate and to be unable to keep pushing organizations forward. We believe that this problem is due to the lack of integration between excellence and agility, which we see as a natural goal for organizations that wish to promote a true culture of excellence in face of highly unstable business environments. This paper presents our research approach to the problem, and early results from investigating the influence of a culture of excellence in promoting an enduring capacity to change.
\end{abstract}

Keywords - Quality, Operational Excellence, Organizational Culture, Organizational Agility

\section{INTRODUCTION}

Excellence programs are quality improvement approaches that have proved to be source of enhanced results [1], and cultural alignment is identified as key success factors for their implementation [2]. However, truth is that after sometime such initiatives stagnate [3], raising the issue of the capacity of these approaches to remain valid in highly unstable business environments. In our view, these limitations have to deal with the way the relationship between culture and excellence has been explored, with organizations focusing more in achieving cultural fit rather than in promoting true cultural transformation, and being unable to fully explore the potential of these programs and to create a clear organizational orientation towards excellence. Such orientation should, in face of highly volatile environments, foster practices and capabilities that allow them to be more adaptable in the long term, creating a resilient culture that promotes adaptability supported in costumer focus, continuous improvement and quality development. If organizations are able to frame the search for quality and excellence in their cultural paradigm, all aspects of their work will be influenced by these principles, and they will have better capacities to answer to sudden market shifts, adapting to changes and turning them into opportunities. In times of highly dynamic and complex business environments, organizational agility should be seen as natural results of culturally sustained operational excellence initiatives [4]. In our view, if the goal of these excellence initiatives is to help organizations improve and develop strategies to satisfy the markets' needs, then adaptability should set as the natural answer an excellenceoriented culture will give to a changing marketplace.

The aim of this project is thus to understand the link between the existence of a sustainable cultural orientation towards excellence and the development of agile practices, and to find evidence that stronger integration of these concepts can help organizations become more adaptable and counter the limitations that excellence initiatives currently face.

\section{LITERATURE REVIEW}

A. The relationship between excellence and culture

The influence of human factors in the successful implementation of operational excellence has been well explored. The Shingo Institute [5] states that excellence frameworks are not agents of transformation by themselves but tools to be used by people in an organization to promote change. Excellence is not made of standard tools but by values, beliefs and practices shared by the workforce, and its success is linked with a full alignment with the culture of an organization [6]. The first step in the implementation of any quality or excellence strategy should be to "build quality into people" [7]. In order to do this, a few factors need to be considered, namely the human nature, needs, motivation, and the environmental and contextual factors [8]. As we understand tools as a means and not an end, we find that most excellent organizations make a good use of their tools by keeping their use simple and by avoiding the replacement of human thinking by these instruments [9]. Despite this focus on the human and social aspects, and their recognition as key success factors of excellence approaches, the truth is that the literature addressing the relationship between excellence and culture is mostly focused in the search for cultural fit. Maul et al. [10] look into the need for a method for cultural analysis prior to the outlining of any improvement program, as only culturally conscious organizations can successfully pursue excellence initiatives, and Aziz and Morita [11] state that the knowledge of the dominant culture is a prerequisite to integrate quality and excellence frameworks. Most of the literature on the problematic of change is addressed from the point of view of cultural fit and adaptation to a set of criteria, and we have identified a knowledge gap regarding the understanding of how do these two concepts and their relationship impact the ability of an organization to succeed in the long term and strive in a changing marketplace [12]. In times of turbulent business environments, organizations need to be more flexible in answering to the requirements of their stakeholders, and excellent organizations should desire to be more agile [13].

\section{B. The need for Organizational Agility}

The pursuit of agility comes as companies try to answer quickly and effectively to the sudden and unexpected 
business environment alterations [14]. Factors for change could come from the marketplace, be promoted by a competitor or by new customer requirements; be a result of a new technology or the outcome of a series of social factors. As these changes become more common, agility gains importance as a survival kit for turbulent markets [15]. But organizational agility is more than a tool of resilience and subsistence in unpredictable environments. It is also a way of being more competitive; it is about cooperating and improving partners; about managing change and using people and information as a competitive leverage [16]. It cannot be regarded as being only reactive, as it is also about sensing, perceiving and anticipating future changes [17]. In order to understand organizational agility, it is essential to understand the roles of its drivers and enablers. The drivers are business environments characteristics which are responsible for triggering change needs, such as customer requirements, competition, technological innovations, and social factors [18]. As for the enablers, they are agile manufacturing practices and capabilities which form the necessary conditions to promote organizational change. They are key success factors that need to be developed, promoted and correctly managed in order to allow a company to deal with change and provide answers to the environments' demands, and include, amongst others, concurrent engineering, integrated information systems, tools and technology, organizational learning, or an agile work environment with employee empowerment and an adequate reward system [19][20][21].

\section{THEORY DEVELOPMENT}

Operational excellence programs are a set of principles and practices that when assimilated by the culture of an organization, and effectively implemented, will promote the development of that organization and the achievement of sustainable organizational results [22]. However, one of the most important reasons why some of these programs fail is because they are not sustainable, i.e., they were not fully absorbed by the culture of the organization [3]. Typically, in these situations there is a "defined time" for the program to be concluded. If an organization is committed in the excellence journey, the implementation of an operational excellence program should be faced as an ongoing project without a defined finish date. In this sense, and although the positive results of culturally integrating quality and excellence programs have been proved throughout the world, there are still severe limitations in the capacity of organizations that engage in these programs to develop the necessary capabilities to promote change in an enduring way. Since many of the excellence-bound approaches remain glued to the perspective of simple cultural fit, and time- or goal-framed change, it is urgent to understand how the establishment of an operational excellence program relates with the ability of being agile, namely by asking: Is the implementation of an operational excellence program able to induce in an organization an enduring capacity to adapt to new business environments?

The organizational culture manages all the aspects related to the daily life of an organization, and it is rooted in the subconscious of workers, influencing process making and strategic decisions. If sudden transformations lead to changes that do not match the established culture, the workforce will fail to recognize them in the cultural framework that, for them, represents success and stability, and will tend to show resistance. Considering that organizational agility is bonded to change, it is necessary to ensure the existence of a cultural background that is able to deal with it. Operational excellence programs should thus focus in creating a long-lasting, change-minding "excellence oriented culture". Accordingly, it is necessary to understand if such orientation can be created by the implementation of excellence initiatives, questioning: Is the implementation of an operational excellence program able to induce in an organizational culture an enduring orientation towards excellence?

Finally, it is fundamental to analyze how an excellence oriented culture is able to foster continuous and sustained improvement to a point of promoting organizational agility and making an organization capable of quickly and efficiently adapting to new business environments. More precisely, it is important to analyze what and how do features of an excellence-oriented culture contribute to inducing in an organization an enduring capacity to adapt to new business environments?

Based on these questions and on the literature review, Figure 1 presents a modeling considering the proposed influence of an excellence-oriented organizational culture in helping organizations in becoming more agile and in developing an enduring capacity to change and finding long-lasting success in a instable business environment.

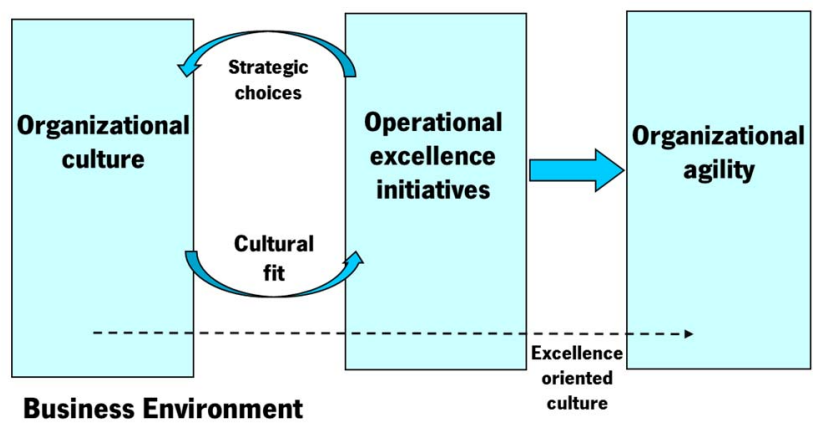

Fig. 1. Conceptual model

\section{METHODOLOGY}

\section{A. Research Process}

The research process to understand if the development of an excellence-oriented culture can be the trigger for the development of agility in organizations has three steps. First, it is necessary to identify and evaluate the existence of operational excellence initiatives; then, to assess the capacity that such initiatives had in changing the culture of a determined group of people or organizational unit; finally, to identify existing practices, enablers and strategies that can support the promotion of organizational agility, and understand if they fall within the same scope and dimensions as the ones of the operational excellence initiatives that have promoted cultural change (figure 2). 


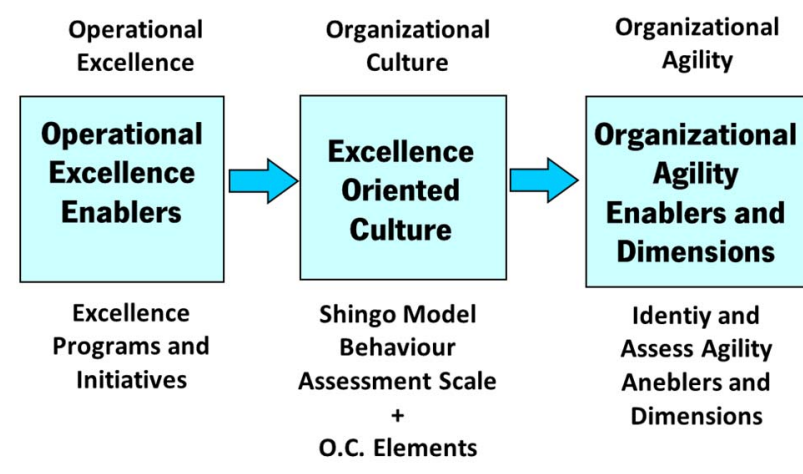

Fig. 2. Research Process

In order to understand what is clearly a context-dependent phenomena, the researchers need to have access to in the field in order to observe, identify and uncover the dynamics and practices of daily work, evading, however, to have a practical participation or influence in any outcomes, which would represent an external interference that detracts reality. Given these facts, and that although some historical record analysis is required, the main focus in understanding a phenomena in a contemporary context, case study methodology stands the most fit to use in this project. Such methodology also deals better with situations where the results rely on multiple sources of evidence, and were data gathered from those sources needs to converge in face of triangulation [23].

\section{B. Operational excellence, an excellence-oriented culture}

In the scope of this project we wish to study the influence of an "excellence oriented culture" in the promotion of agility in an organization. Such a culture is one that shows clear support, motivation and assimilation of the principles of quality and excellence. To confirm the existence of an excellence orientation, it is first necessary to identify, assess and understand the scope in which the operational excellence initiatives were implemented. It is essential to understand the motivation that led to its implementation, so that it is possible to comprehend if the move towards agility was completely self-motivated action in pursuit of a new state of quality and excellence or if it was an isolated event promoted due to external motivations or influence. It is also crucial to understand if there is an organization-wide focus that promotes excellence across the entire organization at the same pace, or if is there a stronger focus only on specific departments and areas. Only then it is possible to draw a picture and recognize the particular identity of each operational excellence initiative, and gain realistic view on the cultural transformations.

Since it is partly a cultural process - the change and formation of a cultural orientation - that we wish to study, the goal is not to quantify or assess the quality or excellence initiatives implemented, but rather to identify them, understand them, and verify how permeable the culture of an organization has been to the changes, tools, and strategies that it promoted. In this sense, evaluating the cultural orientation towards excellence is broad process that will rely on multiple sources of data, encompassing everyone in an organization, from the leadership to the workforce.

\section{Organizational Agility}

Measuring and quantifying organizational agility has been attempted in several different ways, but major limitations and challenges still subside. These limitations are due to the fact of organizational agility being context dependent and not industry specific; to the fact that the same agilitybound strategies might not produce the same results; to the difficulties of tapping into the "soft" domains at human and social dimensions; and to practical conditionings such as the level of detail that is sometimes necessary but that is many times inaccessible or inexistent [24]. Due to these limitations, in the scope of this project we avoid the quantification of the level of agility, rather focusing on identifying practices and strategies that are aligned with the principles, practices and results of organizational agility. In this sense, it is expected that the use and triangulation of multiple sources of qualitative and quantitative data will allow to draw a scenario of the current agile state of agility and to test the relation between the existence of a stronger cultural orientation towards excellence and a greater development of agile capabilities. Our focus is in identifying agility enablers and dimensions and in evaluating the historical records of the companies, in an effort to understand how they performed in face of sudden changes in the business environments (for example, an international crisis scenario, a legislation change or the disruption in the supply of an important raw material or component) and how (or if) they turned those changes in the environment into improvement opportunities. A series of agility enablers, previously identified in literature [12], are grouped into four different dimensions and presented in Table 1. These dimensions represent areas of focus where agile capabilities fall, and are characterized by both enablers and drivers.

\begin{tabular}{|c|c|}
\hline Dimensions & Enablers \\
\hline Manufacturing flexibility & $\begin{array}{c}\text { Concurrent Engineering } \\
\text { Technology }\end{array}$ \\
\hline $\begin{array}{c}\text { Management and strategic } \\
\text { capabilities }\end{array}$ & $\begin{array}{c}\text { Strategic Planning } \\
\text { Supply Chain Integration } \\
\text { Virtual Enterprise } \\
\text { Quality \& Improvement }\end{array}$ \\
\hline $\begin{array}{l}\text { Information management and } \\
\text { organizational learning }\end{array}$ & $\begin{array}{l}\text { Information management } \\
\text { Knowledge management } \\
\text { Learning Organization }\end{array}$ \\
\hline Workforce Agility & $\begin{array}{l}\text { Organizational Culture } \\
\text { Organization Commitment } \\
\text { Employee Empowerment }\end{array}$ \\
\hline
\end{tabular}

\section{Data Collection}

In order test and validate out theory under different cultural, regulatory and environmental contexts, allowing results to be representative of different realities, we wish to develop case studies in different technical industries, both European and American-based companies - thus reducing the impact of cultural, political and geographical factors in the pursuit of quality, excellence, and agility. Such 
different settings will demand different approaches, and a variety of data collection methodologies will be necessary, adapting the tools to each case and its context. Different sources of data are also important as they allow to improve the consistency of constructs and results by crossing outputs [25]. The combined use of different collection methods allows to maximize the confidence and quality of the results and overcome some of the individual limitations of each method, increasing consistency, eliminating bias and promoting a stronger and more concise definition of the constructs under study [26]. The different data collection methods include questionnaires, surveys and documents analysis in the scope of studying excellence initiatives; the analysis of archival records is important for understanding the deployment of excellence initiatives; and observation and ethnography as essential approaches in supporting the investigation of the "cultural orientation towards excellence" and in the identification of the cultural prevalence of enablers and dimensions of organizational agility.

\section{INITIAL CASE STUDY AND RESULTS}

The first organization under study was a Portuguese public owned municipal waste management company, and the data collection efforts resorted to participationobservation, interviews and questionnaires, analysis of processes, documents and archival records, and ethnographic field work. The case study had duration of 10 weeks, covering the organization at all levels: associates (blue- and white-collar), managers and leadership.

The organization was selected as it sets excellence as one of its outspoken operational goals, giving clear emphasis to the term "operational excellence" in their communications, both internal and external. The company, considered a benchmark in Europe, has pursued the development and integration of quality approaches, having started in 2002 with the ISO 9001 quality management system certification in its operations at the waste sorting center, and further implementing it in all its remaining operational areas (energy recovery, organic recovery and landfill technical confinement), until reaching an organization wide integration of its quality management system in 2011. After certification the company did not engage in any new quality or excellence initiatives, having considered but not following through with options such as the European Foundation for Quality Management (EFQM) excellence program - mainly due to the perception that the cost-benefit tradeoff of such approaches wasn't beneficial for them. Instead, it focuses on the existing quality systems and their assessments (internal and external), and in continuous improvement tools as means to achieve enhanced performance - which include a collaboration with the Kaizen Institute and internal continuous improvement teams. The perspective that the company has regarding the part the external quality partners and assessors play is one of not providing prescriptive solutions but to focus on areas for improvement and adapting tools and approaches to the reality of the organization. The top leadership has imprinted a clear focus on sustainability, circular economy, improvement and readiness to change, and there is a solid organizational communication strategy which focuses on reaching out, evolving and educating the public they serve towards a more sustainable behavior in what concerns producing and handling waste, with benefits to their future operations and sourcing. Although different levels of perception were found in different groups (with greater deviation in the manual labor workforce), most workers recognize the success of quality-related strategies, and the importance of promoting agility and readiness to change.

Naturally, there are still a few challenges ahead. Being a public owned company, it faces severe limitations, namely budgetary restrictions and bureaucracy. This leads to the inability to renew its workforce or to be competitive in the labor market, with long public hiring process and salary limitations preventing the company of competing against privates. At the same time budgetary limitations are preventing the regeneration of the workforce, which has been under continuous reduction (between 2 to $6 \%$ year) due to retirements and leaves. This has led to bigger shifts, more monthly working hours, and to an increase in the absenteeism rate. And even though there is a focus on health, and safety training and workplace gymnastics are promoted, most of the absences are primarily due to professional health issues. While it is clear that the environment and sustainability are a central part of the culture, improvement approaches and readiness to innovate and change still face some resistance in different groups, especially within the manual labor workforce.

Nevertheless, it is clear that the organization is aware of these challenges, as it continuously looks to identify and find ways to overcome them. With this purpose, it identifies annually, together with its stakeholders, the biggest challenges it faces and the corrective actions it should be working on. This is done through an inquiry, which has identified precisely the way the company is managing its organizational learning capabilities (2014), the lack of motivation of its workforce (2015), and the lack of flexibility of its workforce and in its operations (2016) as the areas that need further develop an enduring, adaptable culture of excellence.

In this sense, while it is undoubtful that the company is still facing a few challenges, namely the creation of a strong cultural support next to their blue-collar workers, truth is that it has been able to develop a high qualityconcerned, change-ready culture at most levels, with clear strategic implications. Furthermore, it has identified the critical areas that need improvement, and is making efforts to further develop its workforce, integrating tools, systems and people in the pursuit a level of excellence and agility.

\section{ONGOING \& FUTURE WORK}

In an effort to gather further evidence to help us understand the links between excellence, culture and agility, a second case study is being performed in the automotive industry, in an original equipment manufacturer supplying most major automotive brands across the globe. This organization has implemented the model and reached the highest levels of the EFQM excellence program, having received a few recognition 
prizes in its scope. The company is strategically aligned with pursuing excellence, having obtained positive results and attained top levels in the excellence assessments in recent years. There has been an effort to develop a culture of excellence, with broad communication about the values and principles of excellence, and the successes being celebrated and shared with the entire organization and its partners. Furthermore, a considerable number of people have engaged with the early projects that were triggered as EFQM improvement opportunities. At the same time, the organization has shown to have developed some degree of agile capabilities in a few areas: from manufacturing flexibility to the implementation of deep strategical changes, from growing focus on research to innovative products, it was able to attain encouraging results by adapting to the changes in the global marketplace and by taking the most of the opportunities it found.

However, and while most of the changes that happened in the organization in the last years can be tracked to an excellence assessment, truth is that as it moved up the EFQM scale, the feeling that the program is stagnating and that there is less and less room for improvement is shifting the primary focus to improving assessment results and obtaining awards and external recognition. As excellence fades from the daily work focus, there is a risk to the true setting of a culture of excellence, and a limited view of the benefits of developing organization wide agility is set.

The conclusion of this second case study will be essential to understand the stagnation that some excellence approaches face, and its effects both operationally and culturally. In the same sense, in the future, more case studies will be essential to provide further data to analyze and understand these phenomena, and help verify our theory that an excellence-oriented culture can lead to the development of agile capabilities and help overcome some of the current limitations of excellence programs and initiatives.

\section{CONCLUSIONS}

The results of the initial case study support our theory that creating an excellence-oriented culture will have a role in promoting an agile mindset, and in developing capabilities and strategies that support adaptability as an excellence-bound behavior in face of unstable business environments. Although further case studies are necessary to reinforce the conclusions, a very relevant outcome at this point is the feasibility of the adopted methodology, demonstrated with the initial case study's results and validated for use in case studies to come.

\section{ACKNOWLEDGMENT}

The Authors acknowledge the support of Fundação para a Ciência e Tecnologia (Portugal) to this project through grant PD/BD/114149/2016.

\section{REFERENCES}

[1] J.C. Bou-Llusar, A. B. Escrig-Tena, V. Roca-Puig, I. BeltránMartín, "An empirical assessment of the EFQM Excellence Model:
Evaluation as a TQM framework relative to the MBNQA Model”. Journal of Operations Management, 27(1), 1-22, 2009.

[2] J.F. Paris Jr., "State of Readiness", Greenleaf e-book, 2017.

[3] T. Bertels, Buthmann. "Raise the bar". Quality Progress, 46, 28-32, 2013.

[4] S. Vinodh, G. Sundararaj, S. R. Devadasan, "Measuring organisational agility before and after implementation of TADS". The Int.Journal of Advanced Manufacturing Technology, 47(5), 809-818, 2010

[5] Shingo Institute. "Shingo Model", 2014.

[6] M. Araújo, P. Sampaio, "The path to excellence of the Portuguese organizations recognised by the EFQM model". Total Quality Management \& Business Excellence, 25(5-6), 427-438, 2014.

[7] S. Dahlgard-Park., J. J. Dahlgaard, "Excellence-25 year's evolution". Journal of Management History, 13(4), pp. 371-393, 2007.

[8] W.E. Deming, New Economics. Cambridge, MA, USA, 1993

[9] T. Peters, R. Waterman, I. Jones, "In search of excellence: Lessons from America's best-run companies", USA, 1982

[10] R. Maull, P. Brown, R. Cliff., "Organizational culture and quality improvement". International Journal of Operations \& Production Management, 21(3), 302-326, 2001

[11] R.Z.A Aziz, H. Morita, "A Comparative Study of Culture and Performance in TQM and Non-TQM Firms", in Proceedings of the Int. Conf. on Quality 2014, Tokyo. Vol 1-9, pp. 44-55, 2014

[12] A.M. Carvalho, P. Sampaio, E. Rebentisch, "Operational Excellence Programs influence on Organizational Culture Change: a conceptual model proposal", in Proc. Int. Conf. Quality Engineering and Management, Guimarães, Portugal pp. 819-832, 2016

[13] A.M. Ahmed, J.B. Yang, B. G. Dale Self-assessment methodology: the route to business excellence. The quality management journal, vol. 10, pp.1-43, 2003

[14] Y. Yusuf, M. Sarhadi, A. Gunasekaran, "Agile manufacturing: The drivers, concepts and attributes". International Journal of Production Economics, 62(1), 33-43, 1999

[15] E. Bottani, "Profile and enablers of agile companies: An empirical investigation". International Journal of Production Economics, 125(2), pp. 251-261, 2010.

[16] A. Gunasekaran, Y. Yusuf, "Agile manufacturing: a taxonomy of strategic and technological imperatives". International Journal of Production Research, 40(6), pp. 1357-1385, 2002

[17] Z. Zhang, H. Sharifi, "A methodology for achieving agility in manufacturing organizations". International Journal of Operations \& Production Management, 20(4), pp. 496-513, 2000

[18] Y. Tseng, C. Lin, "Enhancing enterprise agility by deploying agile drivers, capabilities and providers". Information Sciences, 181(17), pp. 3693-3708, 2011.

[19] A. Gunasekaran, "Agile manufacturing: a framework for research and development". International Journal of Production Economics, 62(1), pp. 87-105, 1999.

[20] E. Bottani, "On the assessment of enterprise agility: issues from two case studies". Int. Journal of Logistics, 12(3), pp. 213-230, 2009.

[21] E. Conforto, F. Salum, D. Amaral, L. Silva, L. Almeida, "Can agile project management be adopted by industries other than software development?". Project Management Journal, 45(3), 21-34, 2014.

[22] European Foundation for Quality Management (2017), retrieved from http://www.efqm.org/efqm-model/fundamental-concepts

[23] R. K. Yin, "Case study research: Design and methods". Thousand Oaks, California: Sage publications, 2009.

[24] A. Erande, K. Verma, "Measuring agility of organizations-a comprehensive agility measurement tool". International Journal of Applied Management and Technology, 6(3), 2008.

[25] R. Bogdan, S. Biklen, "It is a method-appropriate education: An introduction to theory and methods". Allyn \& Bacon, 2006

[26] D. Silverman, "Doing qualitative research: A practical guide". London: Sage, 2000. 